\title{
Effect of Implant Conditions on the Optical and Structural Properties of $\beta-\mathrm{FeSi}_{2}$
}

\author{
T.M. Butler, C.N. McKinty,K.P. Homewood, R.M. \\ Gwilliam, and K J Kirkby \\ Advanced Technology Institute, \\ School of Electronics and Physical Sciences, \\ University of Surrey, Guildford, Surrey, GU2 7XH, UK \\ k.kirkby@surrey.ac.uk
}

\author{
G. Shao and S Edwards \\ School of Engineering \\ University of Surrey, Guildford, Surrey, GU2 7XH, UK
}

\begin{abstract}
Semiconducting precipitates of $\beta \mathrm{FeSi}_{2}$ have been successfully fabricated in silicon by high dose $\mathrm{Fe}^{+}$implantation (typically $1.5 \times 10^{16} \mathrm{Fe} \mathrm{cm}^{-2}$ at $200 \mathrm{keV}$ ). Room temperature electro luminescence (EL) at $1.5 \mu \mathrm{m}$ has been observed from light emitting diodes (LED's) incorporating this type of structure. This study is to evaluate how the microstructure and optical properties are affected by the implantation parameters, in particular the role of implantation temperature, when high beam current densities are being used. This was done in order to evaluate whether the implant period could be reduced to a commercially realistic time without adversely affecting the optical properties. In this study the implantation temperature was varied and the resulting structures investigated (before and after annealing) using optical absorption, Fourier Transform Infrared Spectroscopy (FTIR), Rutherford backscattering spectroscopy (RBS) and cross sectional transmission electron microscopy (XTEM). A $70 \mathrm{meV}$ decrease in the optical band gap was observed between a sample implanted at $250^{\circ} \mathrm{C}$ and one implanted at $550^{\circ} \mathrm{C}$, a shift in the FTIR spectrum was also observed. RBS and XTEM measurements showed that this change was associated with a change from a surface to a buried silicide "layer", with the latter also exhibiting room temperature EL.
\end{abstract}

$\mathrm{BFeSi}_{2}$, Ion Beam synthesis, optoelectronic devices in silicon, room temperature electroluminescence, FTIR, RBS, Fe implantation into silicon

\section{INTRODUCTION}

Ion Beam Synthesis (IBS - ion beam implantation followed by a subsequent high temperature anneal) has been used for a number of years to fabricate silicide structures in silicon [1]. One group of silicides that has attracted considerable interest are the semiconducting silicides, especially those with a direct gap and a band gap energy smaller than that of silicon. Two such silicides are the beta phase of iron disilicide $\left(\beta-\mathrm{FeSi}_{2}\right)$ $[2,3]$ and diruthenium trisilicide $\left(\mathrm{Ru}_{2} \mathrm{Si}_{3}\right)$ [4].

$\mathrm{FeSi}_{2}$ can exist in two stable phases, the metallic high temperature $\alpha$ phase that has a tetragonal structure (and contains $\sim 18 \% \mathrm{Fe}$ vacancies) and the semiconducting low temperature $\beta$ phase, which has an orthorhombic structure [1$3]$, and a composition close to that of stoichiometric $\mathrm{FeSi}_{2}$. The $\beta$ to $\alpha$ phase transition is reported to occur at about $940^{\circ} \mathrm{C}$ $[1,2]$. There has been some debate in the literature [3] about the nature of the band gap in $\beta-\mathrm{FeSi}_{2}$, and there are now a considerable number of experimental observations, which indicate a direct gap of $0.8-0.9 \mathrm{eV}[2,3]$. These results point to a number of potential applications for $\beta-\mathrm{FeSi}_{2}$ in such areas as solar cells, light emitters and detector technology. The group at Surrey showed that $\beta-\mathrm{FeSi}_{2}$ fabricated by IBS has a direct gap and can produce room temperature electro luminescence (EL), albeit weakly, at approximately $\lambda=1.5$ $\mu \mathrm{m}[5,6]$.

The commercial exploitation of ion beam synthesised $\beta$ $\mathrm{FeSi}_{2}$ will require increases in beam current to enable material fabrication on reasonable time scales. Hitherto most material has been fabricated at medium to low beam currents, typically a few hundred micro amps or less. In this paper we present recent work where we have extended synthesis to implantation in the milliamp range. This use of increased beam current reduces the implant time to commercially realistic values $(\sim 30$ minutes to implant a $100 \mathrm{~mm}$ wafer to a dose of $1.5 \times 10^{17} \mathrm{Fe}$ $\mathrm{cm}^{-2}$ ). At high currents very different growth and formation of the silicide has been observed to occur with only small changes in the process parameters, and this will be described in detail below

\section{EXPERIMENTAL}

A commercial ion implanter, a Danfysik 1090, was used to implant $100 \mathrm{~mm}$ diameter (100) single crystal $\mathrm{n}$-type $\mathrm{Si}$ wafers with $180 \mathrm{keV} \mathrm{Fe}{ }^{+}$to a dose of $1.5-2 \times 10^{17} \mathrm{Fe} \mathrm{cm}^{-2}$. The implant area was $49 \mathrm{~cm}^{2}$. The wafers were implanted using a beam current on sample of either $1.5 \mathrm{~mA}$ or $0.6 \mathrm{~mA}$. The wafers were attached to a liquid-nitrogen cooled chuck stage and were heated, during implantation, using the power of the incident ion beam. The wafer achieved its equilibrium temperature after 1-2 minutes of implantation. The temperature at the centre of the wafer was measured during implantation using an optical pyrometer. For a beam current of $1.5 \mathrm{~mA}$ the temperature at the centre of the wafer was approximately $500^{\circ} \mathrm{C}$. For the lower beam current $(0.6 \mathrm{~mA})$ the temperature was closer to $250^{\circ} \mathrm{C}$. The total implant time ranged from about 30 minutes for the higher beam current to 135 minutes for the lower. 
After implantation the wafers were cut into smaller samples some of which were annealed. Annealing was carried out in a Process Products Corporation optical furnace using a nitrogen ambient, for 18 hours at $900^{\circ} \mathrm{C}$. Structural and optical measurements were carried out on both as-implanted and annealed material. Cross-sectional TEM (XTEM), was used to provide structural and phase information on the samples. Rutherford backscattering (RBS) measurements using $1.5 \mathrm{MeV}$ $\mathrm{He}$ ions were undertaken to study the iron depth distribution as a function of implant and annealing conditions.

Room temperature optical absorption measurements were used to yield the optical band gap energy of the material. A tungsten lamp was used as the source in the wavelength range $1100-1700 \mathrm{~nm}$. A liquid nitrogen cooled germanium (PIN) detector connected to a grating spectrometer was used for these absorption measurements. Full details of the experimental system used can be found elsewhere [2,11]. Fourier transform infrared (FTIR) spectroscopy was used to determine the phonon spectra of the silicide material, using a Nicolet Protégé 460 spectrometer in the range $600-225 \mathrm{~cm}^{-1}$

\section{RESULTS AND DISCUSSION}

\subsection{Structural Measurements}

The RBS spectra of as-implanted and annealed samples implanted at the lower $\left(250^{\circ} \mathrm{C}\right)$ and higher $\left(550^{\circ} \mathrm{C}\right)$ implant temperatures are shown in beam currents in Figures 1 and 2, respectively. The implanted dose was $1.5 \times 10^{17} \mathrm{Fe} \mathrm{cm}^{-2}$ in each

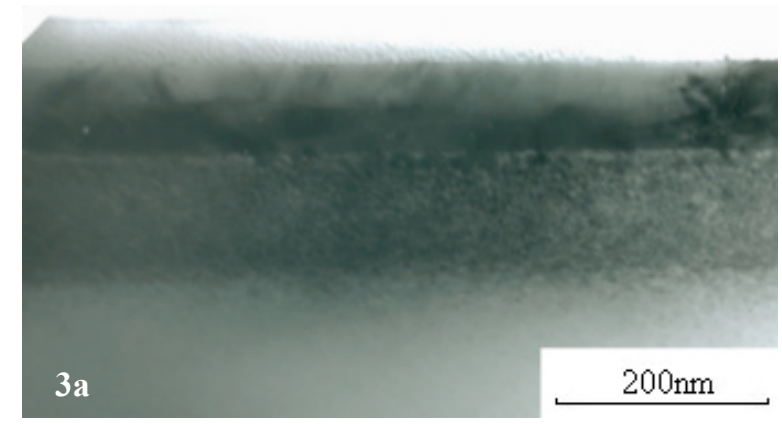

Figure 3: XTEM for the sample implanted with $1.5 \times 10^{17} \mathrm{Fe} \mathrm{cm}^{-2}$ at $250^{\circ} \mathrm{C}$, (a) as-implanted (b) annealed (18 hrs at $\left.900^{\circ} \mathrm{C}\right)$
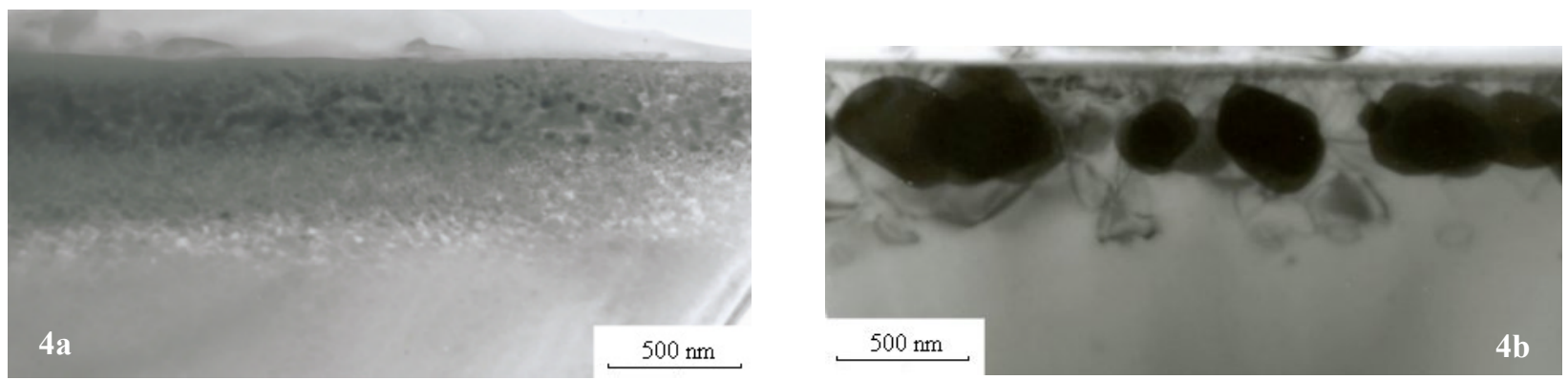

Figure 4: XTEM for the sample implanted with $1.5 \times 10^{17} \mathrm{Fe} \mathrm{cm}^{-2}$ at $550^{\circ} \mathrm{C}$, (a) as-implanted (b) annealed $\left(18 \mathrm{hrs}\right.$ at $\left.900^{\circ} \mathrm{C}\right)$

case. . The data was analysed using the IBA Data Furnace [7]. From the RBS spectra it is clear that the depth profile of the iron, and its behaviour up on annealing, is quite different at the two implant temperatures. For the sample implanted at the

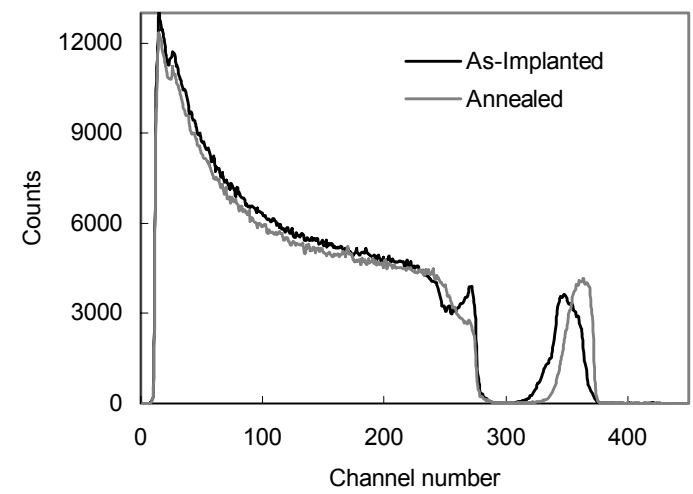

Figure 1: Random RBS spectra for the sample implanted with $1.5 \times 10^{17} \mathrm{Fe} \mathrm{cm}^{-2}$ at $250^{\circ} \mathrm{C}$, for as-implanted annealed $\left(18 \mathrm{hrs}\right.$ at $\left.900^{\circ} \mathrm{C}\right)$ samples

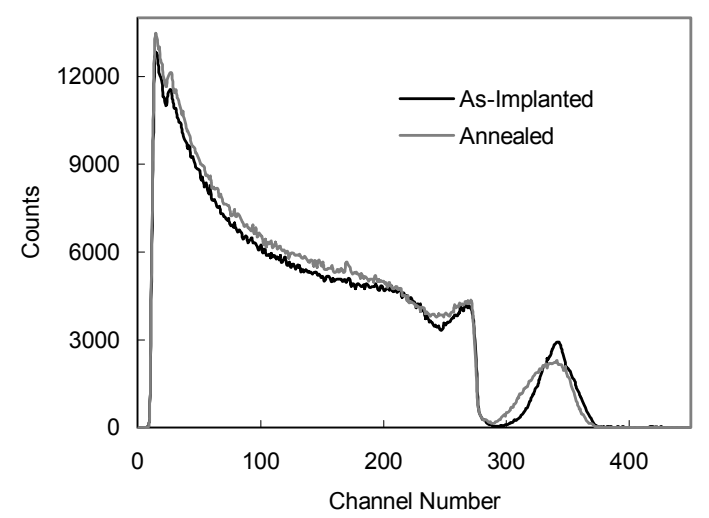

Figure 2: Random RBS spectra for the sample implanted with $1.5 \times 10^{17} \mathrm{Fe} \mathrm{cm}^{-2}$ at $550^{\circ} \mathrm{C}$, for as-implanted annealed $\left(18 \mathrm{hrs}\right.$ at $\left.900^{\circ} \mathrm{C}\right)$ samples

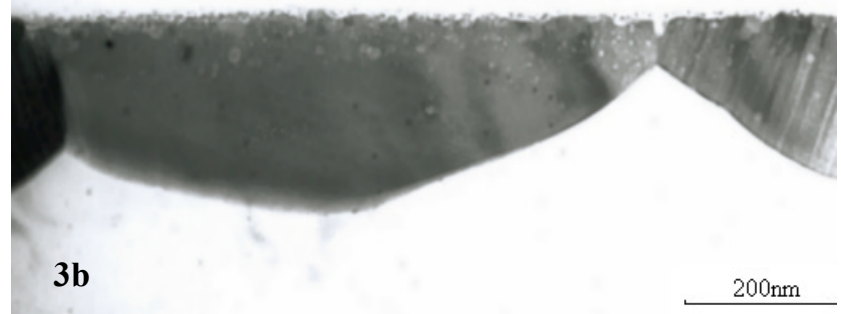

higher temperature (Fig. 2), the position of the peak in the iron depth distribution did not change significantly after annealing, whereas for the sample implanted at the lower temperature (Fig. 1) it shifted towards the surface after annealing. In order 
to obtain further information into how these structures develop during implantation and annealing cross sectional transmission electron microscopy (XTEM) was undertaken. Figures 3 and 4 show XTEM micrographs for the sample implanted at $250^{\circ} \mathrm{C}$ and $550^{\circ} \mathrm{C}$ before and after annealing (Figure $3 \mathrm{a}$ and $3 \mathrm{~b}$ respectively for the $250^{\circ} \mathrm{C}$ implant and Figure $4 \mathrm{a}$ and $4 \mathrm{~b}$ for the $550^{\circ} \mathrm{C}$ implant). For the lower temperature implant, the silicon is amorphised during implantation and its subsequent regrowth during annealing facilitates the transport of iron towards the surface ahead of the regrowth front. Thus the structure after annealing consists of a continuous layer of polycrystalline $\beta \mathrm{FeSi}_{2}$ some $150 \mathrm{~nm}$ thick. The sample implanted at the higher temperature retains its crystallinity during implantation. Fig. 4a indicates the presence of small precipitates of $\mathrm{\beta FeSi}_{2}$, which range in size and density following the implanted depth distribution, with the largest precipitates being found at the peak of the distribution. When this sample is subsequently annealed at $900^{\circ} \mathrm{C}$ these precipitates grow at the expense of smaller precipitates surrounding them in a manner similar to that described for oxygen implanted silicon [8-10]. After annealing at $900^{\circ} \mathrm{C}$ for 18 hours these precipitates are typically $200 \mathrm{~nm}$ in diameter.

\subsection{Optical Measurements}

Room temperature optical absorption measurements were carried out to determine the effect of the above structural difference on the band gap energy of the materials. Figure 5 plots the square of the absorption coefficient (alpha squared) verses photon energy for samples of the two types of structure after annealing. The linear regions of the plot are indicative of a direct band gap semiconductor. Extrapolation to the baseline

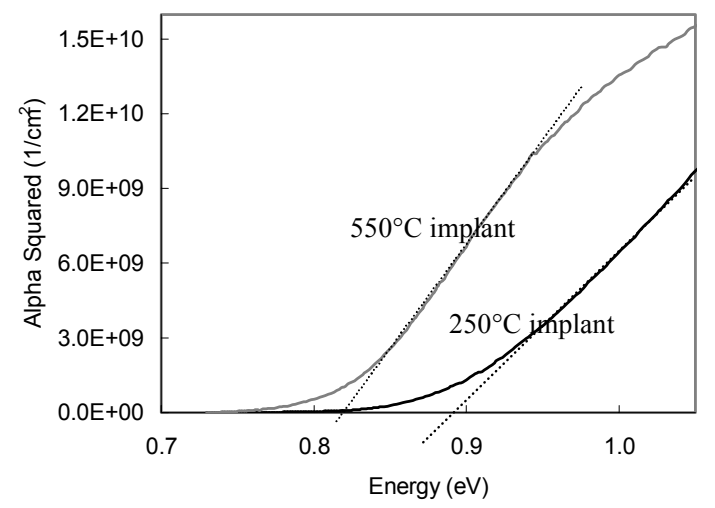

Figure 5: Absorption coefficient squared (alpha squared) vs energy plot for samples implanted with $1.5 \times 10^{17} \mathrm{Fe} \mathrm{cm}^{-2}$ at $250^{\circ} \mathrm{C}$, and $550^{\circ} \mathrm{C}$ annealed $\left(18 \mathrm{hrs}\right.$ at $\left.900^{\circ} \mathrm{C}\right)$.

yields the value of the band gap energy, this is found to be $0.82 \mathrm{eV}$ for the sample implanted at $550^{\circ} \mathrm{C}$ and $0.89 \mathrm{eV}$ for the $250^{\circ} \mathrm{C}$ implant. The below band gap absorption in Figure 5 has been previously reported for $\beta-\mathrm{FeSi}_{2}$, and can be described by the usual Urbach expression [11].

These results are consistent with those reported in the literature. It has been observed that the magnitude of the band gap is different for continuous layers of $\beta-\mathrm{FeSi}_{2}$ than for precipitate structures (the latter having the smaller band gap) [12]. Theoretical reports by Miglio et al. [13] suggest a strain dependence of the band gap value of $\beta-\mathrm{FeSi}_{2}$. The strain for the surface $\mathrm{FeSi}_{2}$ layer would be expected to be lower than a precipitate structure.

In the infrared region between 180 and $500 \mathrm{~cm}^{-1} \beta-\mathrm{FeSi}_{2}$ exhibits an intense phonon spectrum [14-16]. It has been shown that this phonon spectrum varies with the structural quality of the layers, crystallographic orientation of the precipitates, precipitate size and thermal treatment of $\beta-\mathrm{FeSi}_{2}$ [14-16]. The phonon spectrum, measured by FTIR spectroscopy, for the samples implanted at $250^{\circ} \mathrm{C}$ and $550^{\circ} \mathrm{C}$ is shown in Fig. 6. Examination of Fig. 6 reveals that while both samples show the characteristic peaks associated with $\beta$ $\mathrm{FeSi}_{2}$, the two spectra are shifted by $10 \mathrm{~cm}^{-1}$ with respect to each other and the relative intensity of the peaks is quite different.

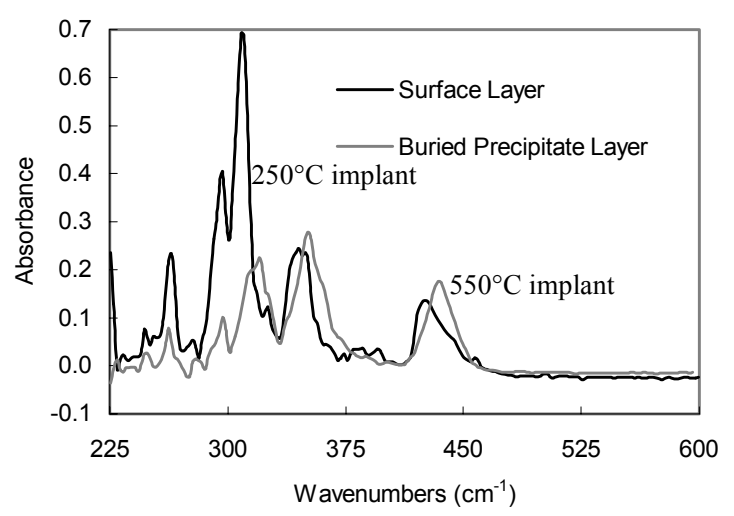

Figure 6: FTIR spectra after annealing at $900^{\circ} \mathrm{C}$ for 18 hours for the samples implanted with $1.5 \times 10^{17} \mathrm{Fe} \mathrm{cm}^{-2}$ at $250^{\circ} \mathrm{C}$, and $550^{\circ} \mathrm{C}$.

In their paper G. Guizzetti et al. [16] reported far infrared reflectivity measurements with polarised light on small singlecrystalline $\beta-\mathrm{FeSi}_{2}$ specimens. They found significant differences between the IR spectra taken at different polarisations with respect to the crystal axis. This anisotropy is evident in Figure 6 as well. The XTEM measurements on the surface layer and buried precipitate materials showed different crystallographic orientations between the two cases. In the surface silicide case the dominant orientation was dominated by the type I orientation of low lattice mismatches, while in the buried precipitate case it was random due to relaxation from the highly strained prior type II orientation. Detail information for crystallographic analysis of IBS iron disilicides was presented in a previous elsewhere [17]. The difference in the IR spectra in Fig. 6 also reflects this difference in orientation

\section{CONCLUSIONS}

Two quite different types of structure are produced when $\mathrm{Fe}$ is implanted at $250^{\circ} \mathrm{C}$ and $550^{\circ} \mathrm{C}$ at relatively high beam current densities. For the lower temperature implant amorphisation occurs during implantation and the subsequent regrowth of this amorphous layer, during annealing at $900^{\circ} \mathrm{C}$ 
for 18 hours, facilitates the migration of iron towards the surface to form a continuous $150 \mathrm{~nm}$ thick polycrystalline layer of $\mathrm{\beta FeSi}_{2}$. For the higher temperature implant amorphisation does not occur and a buried layer of discrete $\beta \mathrm{FeSi}_{2}$ precipitates typically $200 \mathrm{~nm}$ in diameter is formed after annealing. A $70 \mathrm{meV}$ decrease in the optical band gap is observed in between a sample implanted at $250^{\circ} \mathrm{C}(0.89 \mathrm{eV})$ and the one implanted at $550^{\circ} \mathrm{C}(0.82 \mathrm{eV})$, a $10 \mathrm{~cm}^{-1}$ shift in the FTIR spectrum of is also observed.. This study has shown that it is possible to fabricate $\beta-\mathrm{FeSi}_{2}$ using a commercial implanter in a realistic timescale (30 minutes). However, the implant temperature must be carefully monitored to ensure that amorphisation does not occur.

\section{.ACKNOWLEDGMENT}

This work is funded by grants ESPRIT MEL-ARI 28740 SILITE and UK EPSRC GR/L84773. The authors thank Prof $\mathrm{R}$. Webb and Dr C. Jeynes for useful discussions on the RBS data.

\section{REFERENCES}

1 S. Mantl, Nuclear Instruments and Methods in Physics Research B 80/81, 895 (1993). General ref Mantl et al

2 K.J. Reeson, M.S. Finney, M.A. Harry, S.V. Hutchinson, Y.S. Tan, D. Leong, T.R. Bearda, Z. Yang, G. Curello, K.P. Homewood, R.M. Gwilliam and B.J. Sealy, Nuclear Instruments and Methods in Physics Research B 106, 364 (1995).

3 H Katsumata, Y Makita, N Kobayashi, H Shibata, M Hasegawa, I Aksenov, S Kimura, A Obara, S Uekusa J. Appl. Phys. 80 (1996) 5995

4 J.S. Sharpe, Y.L. Chen, R.M. Gwilliam, A.K. Kewell, C.N. McKinty, M.A. Lurenço, G. Shao, K.P. Homewood and K. Reeson Kirkby, Applied Physics Letters 75, 1282 (1999).

5 D. Leong, M. Harry, K.J. Reeson and K.P. Homewood, Nature 387, 686 (1997)

6 K J Kirkby, M Lourenco, T M Butler, K Homewood and C M McKinty Light Emission from Semiconducting Silicide Nanostructures, Physics, Chemistry and application of Nanostructures (invited), World Scientific, 76-87, (2001)

7 N.P. Barradas, C. Jeynes and R.P. Webb, Applied Physics Letters 71, 291 (1997)

8 K Izumi, M Doken, and H Ariyoshi Electronics Letters 14 (1978), 593

9 K J Reeson, C D Marsh, R J Chater, J A Kilner, K N Christensen, A K Robinson, P L F Hemment, G Harbeke, E F Steigmeier, G R Booker and G K Celler, Microelectronic Engineering, 8 (1989)163

10 C Jaussaud, J Margail, J Stoemenos and M Bruel, Proc Materials Research Soc, 100 (1988) 17 and 100, (1988)107

11 Z. Yang, K.P. Homewood, M.S. Finney, M.A. Harry and K.J. Reeson, J. Appl. Phys. 78, 1958 (1995).

12 M.G. Grimaldi, S. Coffa, C. Spinella, F. Marabelli, M. Galli, L. Miglio and V. Meregalli, Journal of Luminescence 80, 467 (1999).

13 L. Miglio, V. Meregalli and O. Jepsen, Applied Physics Letters 75, 385 (1999).

14 G. Guizzetti, F. Marabelli, M. Patrini, Y. Mo, N. Onda and H. Von Känel, Mat. Res. Soc. Symp. Proc. 320, 127 (1994).

15 F. Fenske, H. Lange, G. Oertel, G.U. Reinsperger, J. Schumann, B. Selle, Materials Chemistry and Physics 43, 238 (1996)

16 G. Guizzetti, F. Marabelli, M. Patrini, P. Pellegrino, B. Pivac, L. Miglio, V. Meregalli, H. Lange, W. Henrion and V. Tomm, Physical Review B $\mathbf{5 5}, 14290$ (1997).

17 G. Shao and K.P. Homewood, Intermetallics 8, 1405 (2000). 